\title{
The Role of Teachers in Guiding Students to Use Smart Phones in their Learning Process from Teachers' Viewpoint
}

\author{
Suleiman Mohammad Abu Safiyah \\ The Ministry of Education \\ sulimanabusafeh@gmail.com
}

Received 6/6/2021

Accepted 17/10/2021

\begin{abstract}
:
The study aims to identify the role of teachers in guiding students to use smart phones in their learning process, where the researcher used the descriptive analytical approach, and the questionnaire consists of (25) paragraphs as a tool for collecting study data after verifying its validity and reliability, while the sample was chosen by the researcher from his community consisting of (2401) teachers using the stratified random method, which consisted of (360) teachers, and the Statistical Package for Social Sciences (SPSS) program was used to analyze the data. The results of the study show that there was a role for teachers in directing public secondary school students affiliated to the Rusifa District to use smart phones in their learning process came in a medium degree, and an arithmetic mean of (3.37). The results also show that there were no statistically significant differences at the significance level $(\alpha \geq 0.05)$ between the responses of the sample members about the role of teachers in directing public secondary school students affiliated to the Rusifa District to use smart phones in their learning process according to the study variables: Gender, Academic Qualification, and Number of Years of Experience. Based on the results, the researcher recommends: the need for school officials to realize this dangerous phenomenon and work to confront it by giving students homework urging them to use their smart devices for doing it, and guiding and educating teachers and students on the optimal use of mobile phones in the learning process.
\end{abstract}

Keywords: Role of the Teacher, Smart Phones, Learning Process. 


\title{
دور المطلمين في توجيه الطلبة لاستخام الهواتف الذكية في عملية تعلهم من وجهة نظرهم
}

\author{
سليمان محمد أبو صفية \\ وزارة التربية والتعليم
}

sulimanabusafeh@gmail.com

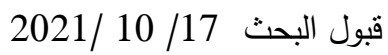

استلام البحث 6 / 621 (2021

الملخص:

تهدف الدراسة للتعرّف إلى دور المعلمين في نوجيه الطلبة لاستخدام الهواتف الذكية في عملية تعلمهم، حيث استخذم الباحث المنهج الوصفي التحليلي، والاستبانة المكونة من (25) فقرة كأداة لجمع بيانات الدراسة بعد النأكد من صدقها وثباتها، أما العينة فقد اختارها الباحث من مجتمعها

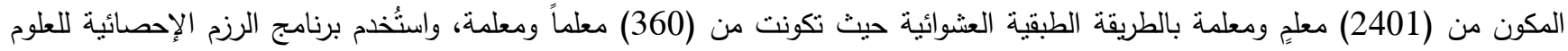
الاجتماعية (SPSS) لتحليل البيانات. وقد أظهرت نتائج الدراسة: أنّ هناك دورا للمعلمين في نوجيه طلبة المدارس الثانوية الحكومية التابعة للواء الرصيفة لاستخدام الهواتق الذكية في عملية نعلمهم جاءت بدرجة منوسطة، وبوسط حسابي بلغ (3.37). كما أظهرت النتائج عدم وجود فروق

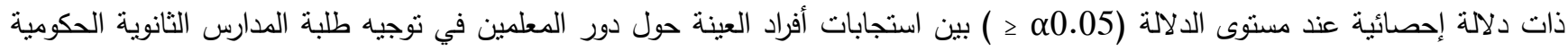

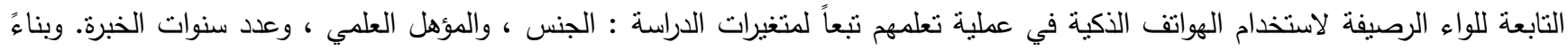
على النتائج يوصي الباحث بضرورة استدراك القائمين على الددارس لهذه الظاهرة الخطيرة والعمل على مواجهتها من خلال إعطاء واجبات دراسية

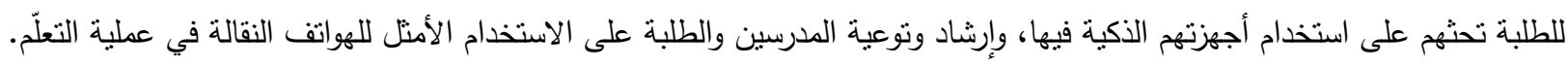
الكلمات المفتاحية: دور المعلم، الهواتف الذكية، عملية التعلّم.

ويشير التميمي(2) إلى أنه وعلى الرغم من أنّ الإنترنت يُعد الأبرز في

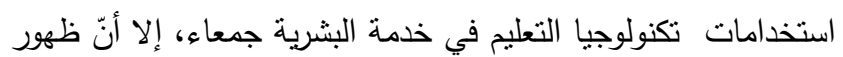

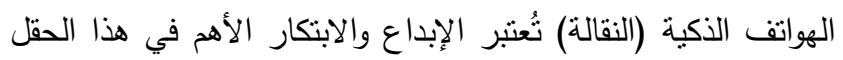
على اعتبارها من أكثر وسائل الاتصال والتواصل التكنولوجية تأثئراً على علاقات وتفاعلات الأفراد في المجتمعات على اختلاف مستويات الاتل

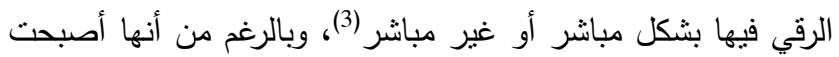

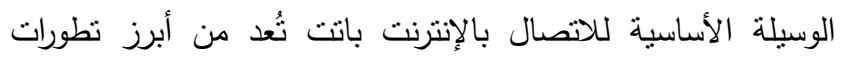

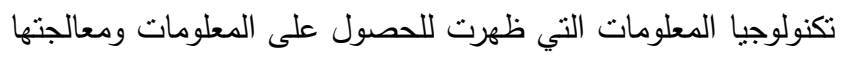

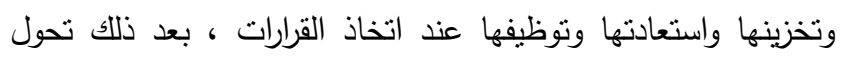
العصر الصناعي إلى عصر المعرفة في إدخال تقنيات الاتصال

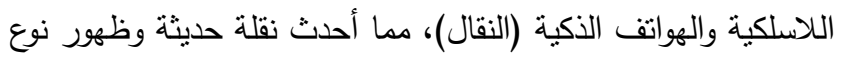

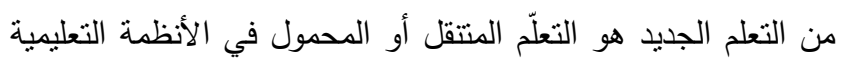
على اعتبارها من أنواع وأشكال التعلم عن بُعد، ونمطاً نعليماً إلكترونياً يعتبر فريداً ومكملاً لعمليه التعليم من خلال استخدام الوسائل والأجهزة

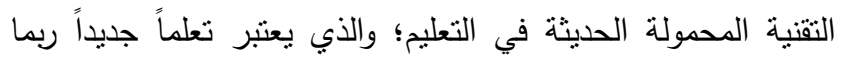

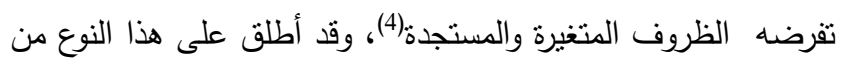

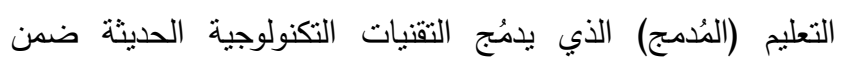

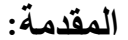

إن من يُمعن النظر إلى الدول والمجتمعات المعاصرة يلاحظ أنها تتشهد تحديات عديدة فرضتها عليها التغيرات المتسارعة في المجال

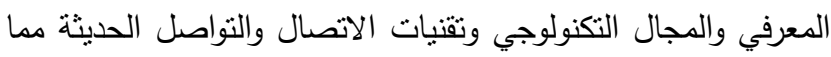

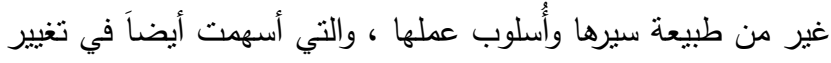

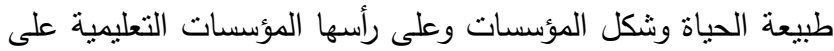
اختلاف مستوياتها، فعمليتا التعليم والتعلم من المفاهيم التي تأثرت بهذا التطور والتغير المنسارع، حيث تمثل ذلك من خلال بروز أثنكال

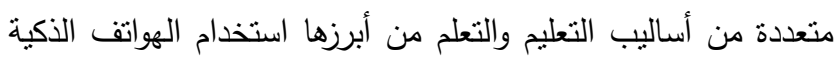

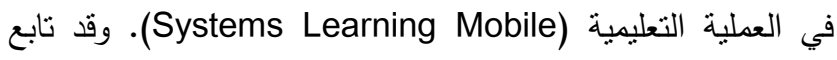
هذا النطور والتغير المنسارع والكبير الذي شهده العالم تطور في مجال تكنولوجيا التعليم، حيث تولد عنه إنتاج وسائط حديثة للتواصل

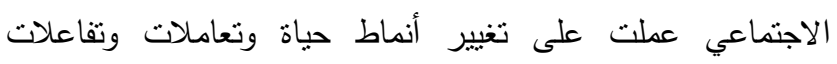
وطبيعة علاقات الأفراد اليومية، بالإضافة إلى تغير في جوانب حياتهم السياسية والنفسية والاقتصادية والاجتماعية، وطالت الجوانب الصحية

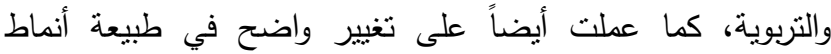
وأساليب الاتصال والتواصل التي تعوّد عليها الأفراد في مجتمعهم علئ. 
الاقتصار في استخدامها على الألعاب وإرسال واستقبال

المكالمات الهاتفية وغيرها من الاستخدامات غير التعليمية.

أهداف الدراسةة: - أل

هدفت الدراسة للتعرف إلى دور المعلمين في توجيه طلبة المدارس

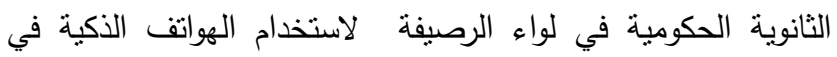

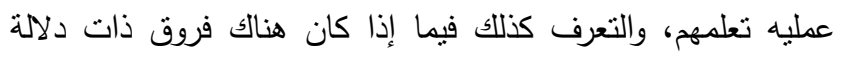
إحصائية عند مستوى الدلالة (0.05 > د ) بين المنوسطات الحسابية

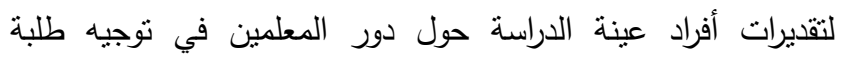
المدارس الثانوية الحكومية في لواء الرصيفة لاستخدام الهواتف الذكية في عمليه تعلمه تبعاً للمتغيرات الثخصية لأفراد عينة الدراسة: (الجنس، المؤهل العلمي، سنوات الخبرة).

مصطحات الاراسة:

الدور: عرفه البدري(5) على أنه مجموعة من الأنشطة والمهام

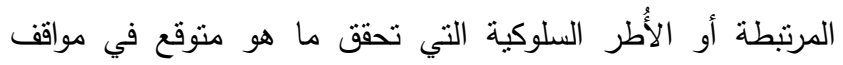

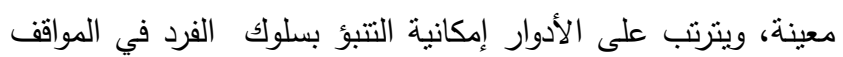

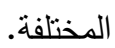

دور المعلم: يعرفه الباحث إجرائياً بأنه مجموعة الأنشطة التربوية

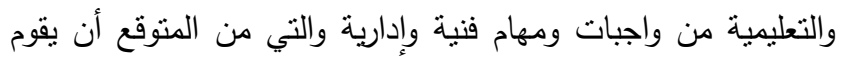

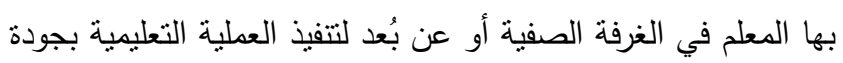

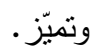

الهواتف الأكية في العملية التعليمية: يعرّفها الدليمي (6) بأنها الوسيلة التعليمية التي يستخدمها المعلمون في الكثير من الددارس؛ ونساعد الطيه

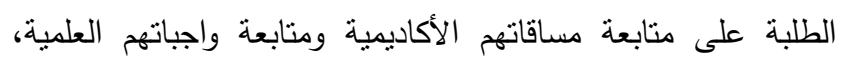

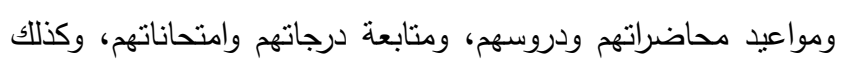

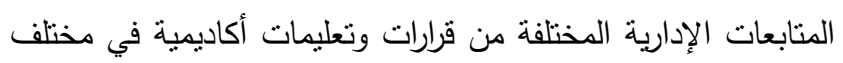

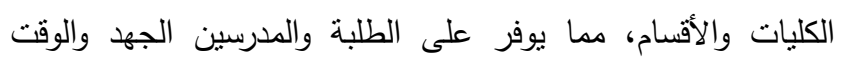

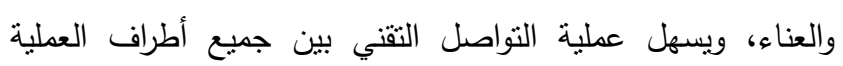

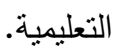

ويُعرَف الباحث الهاتف الذكي إجرائياً بأنه الجهاز الذي يحمله

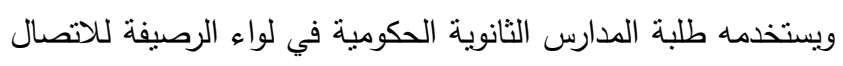

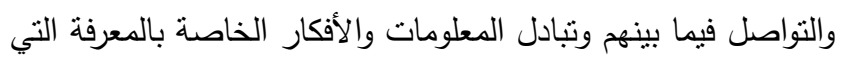
يتلقونها من خلال المساقات والمناهج الدراسية التي يدرسونها، ويحتوي

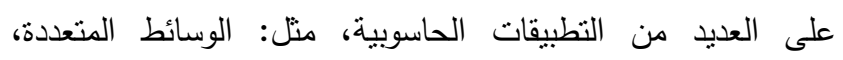
والانترنت، والبلوتوث...الخ.

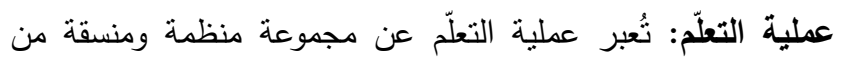

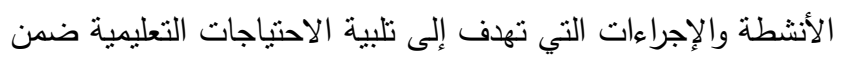

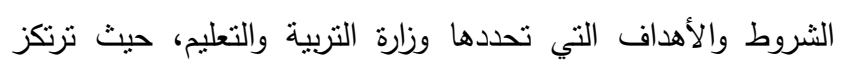

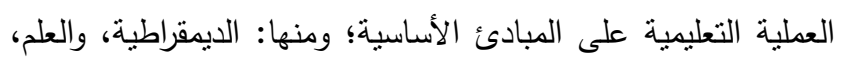

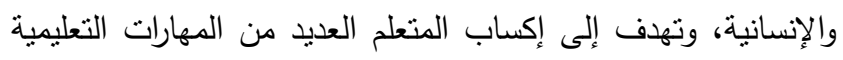

الحصة الدراسية، ولكن إبّانَ الظروف التي مرت بها الدول

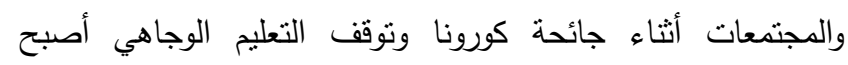

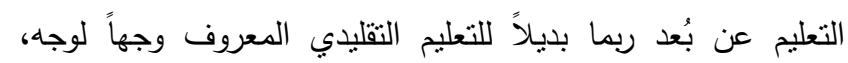
والمُدمج في الغرفة الصفية. مشكلة الدراسة: إنّ الملاحِظ لواقع استخدام الهواتف الذكية في التعاملات والتفاعلات

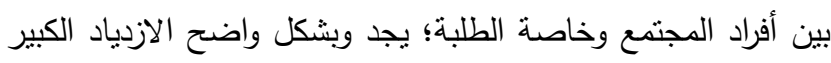

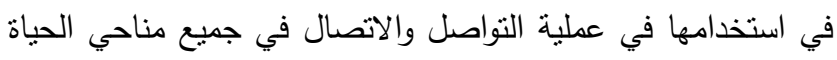

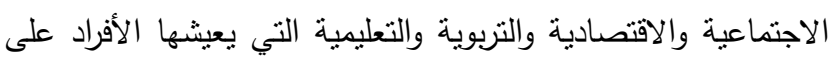

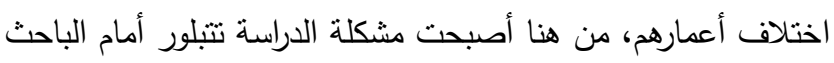
في التعرّف إلى دور المعلمين في توجيه الطلبة لاستخدام الهواتق

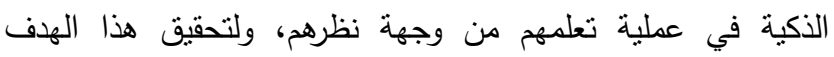

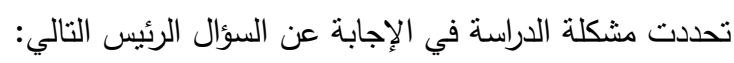

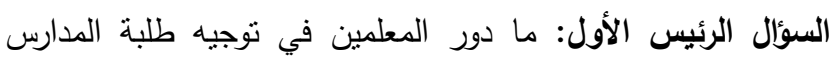

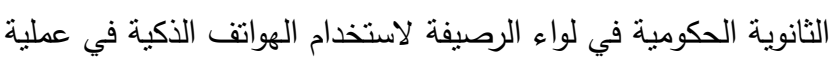
تعلمهم من وجهة نظرهم؟ ويتفرع عنه الأسئلة التالية: 1. ما درجة ممارسة المعلمين لدورهم في نوجيه طلبة الددارس الاسنها

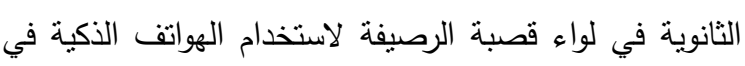
عملية تعلمهم من وجهة نظرهم؟ 2. هل توجد فروق ذات دلالة إحصائية عند مستوى الدلالة

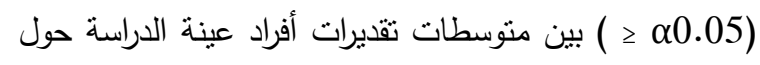

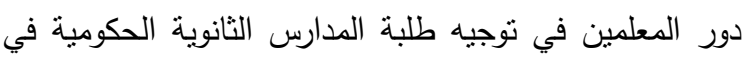

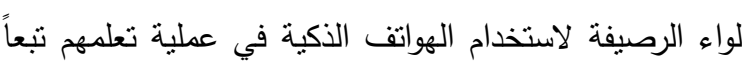
للمتغيرات الثخصية لأفراد عينة الدراسة (الجنس، المؤهل

$$
\text { العلمي، عدد سنوات الخبرة)؟ }
$$

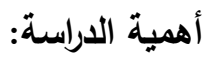

تبرز أهمية هذه الدراسة من أهمية موضوعها الذي تنتاوله والذي يتعلق بالتعرف إلى دور المعلمين في توجيه طلبة المدارس الثانوية الهية

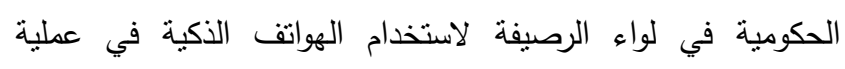

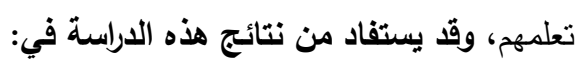

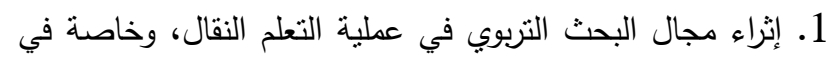

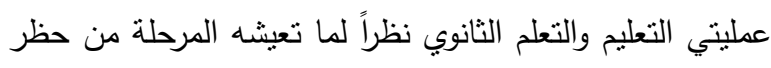
بسبب جائحة كورونا واغلاق للمدارس وتغير طبيعة التعليم إلى لى لئل التعليم عن بُعد. 2. فتح المجال أمام باحثين آخرين وخاصة المهتمين بالتسارع

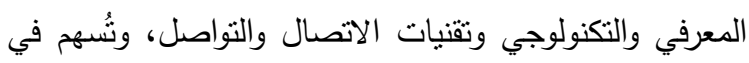

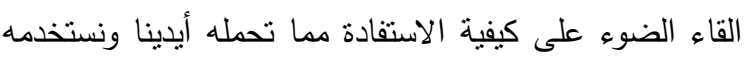

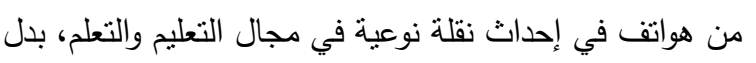


محاضراتهم ودروسهم، ومتابعة درجاتهم في الامتحانات، وكذللك

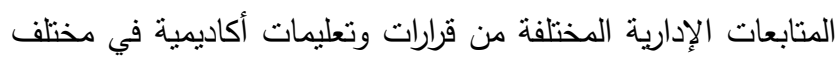
الكليات والأقسام ، مما يوفر على الطلبة وأعضاء هيئة التدريس الجها والوقت والعناء، ويسهل عملية التواصل التقني بين جميع أطراف العملية التعليمية.

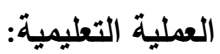
بثير مفهوم التعليم إلى عمليات التفاعل المتبادل بين المعلم والمتعلمين، ويفترض أن تؤدي إلى تغيير إيجابي في السلوك لدى المتعلمين، فكل ما يجري في الغرفة الصفية من أعمال وأنشطة وتفاعلات وتتظيم لعمليتي التعليم والتعلم، يكون هادفاً مهماً في بناء

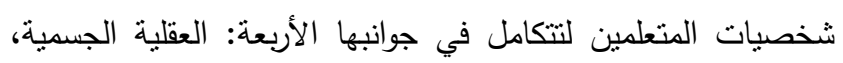
الانفعالية، الاجتماعية(10). فدور المعلم في عملية التعليم والتعلم يعتبر عملاً جليلاً ضمن هذه العملية من خلال خدمة المجتمع المحلي، فرسالته عظيمة؛ لأنه المُحافظ على التراث الحضاري من خلال نقله من جيل إلى جيل، وهو الرائد والموجه نحو المثل العليا التي تحتاجها الحياة المعاصرة؛ لذا فإنّ مهنته تسمو على كل مهنة إذا ما قام بالأعمال والمهارات المطلوبة منه، وهي: التأثير في المجتمع عن طريق الأبناء (الطلبة)، والتأثير غير المباشر في المجتمع عن طريق وهيت غرس القيم والمنل العليا التي يتصف بها المعلم(11). فالعملية التعليمية تُعبر عن مجموعة منظمة ومنسقة من الأشطة والإجراءات التي تهدف إلى تلبية الاحتياجات التعليمية ضمن الشروط والأهداف التي تحددها التشريعات الناظمة لهذه لعملية في أي دولة أو مجتمع، فهي تزتكز على المبادئ الأساسية؛ ومنها: *الديمقراطية. *العلم. *الإنسانية، وتهدف إلى إكساب المتعلم العديد من المهارات التعليمية التي تجعل من شخصيته أكثز قوةً واتزانا، وتساهم في إتاحة فرص

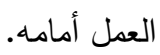

\section{عناصر العملية التعليمية:}

تتضمن العملية التعليمية مجموعة من العناصر، تذكر جابر(12) أهمها بما يلي: 1. المعلم: يُعتبر المعلم العنصر الأساسي الأول، والأكثر أهمية من بين عناصر العملية التعليمية، فهو المخطط والمنظم والمنفذ لهذه العملية.

2. المنهاج: هو المادة العلمية (النظرية والعملية) التي يتلقاها المتعلمون والذي يجب الاهتمام بمحتواه، ليساير التطورات والتغيرات المتسارعة؛ بحيث يتضمن ويركز على تعليم وإكساب المتعلمين المهارات والمعلومات الرئيسية في مواضيع مختلفة؛ مثل: *ثبناء

$$
\text { المعرفة *التغذية. *النظافة.... وغيرها. }
$$

3. الصف الدراسي: وهو المكان الذي يجب الاهتمام في نوفيره كبيئة تعليمية مناسبة تتوفر فيه البنية التحنية التي تخدم المعلم والمتعلم
التي تجعل من شخصيته أكثر قوةً واتزانا، وتشاهم في إناحة فرص

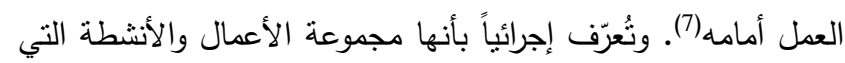
يؤديها المعلم في الحصة الدراسية أو عن بُعد؛ وضمن مادة علمية أو عملية (المنهاج) تحددها التشريعات الناظمة للتعليم في الدولة لتمية وإعداد المتعلمين (الطلبة) من جميع جوانب شخصيتهم. حدود ومحددات الدراسة التزمت الدراسة بالحدود التالية: أ. أ. حدود الدراسة الحدود الموضوعية: التعرف إلى درجة ممارسة المعلمين لدورهم في توجيه طلبة المدارس الثانوية في لواء الرصيفة لاستخدام الهواتف الذكية في عملية تعلمهم من وجهة نظرهم. الحدود المكانية: اقتصرت الدراسة على طلبة المدارس الثانوية الحكومية في لواء الرصيفة. الحدود الزمانية: أجريت الدراسة في الفصل الثاني من العام الدراسي لردي • (2021/2020) ب. محددات الاراسة

تحدد تعميم نتائج هذه الاراسة على مجتمعات أُخرى بما يلي:

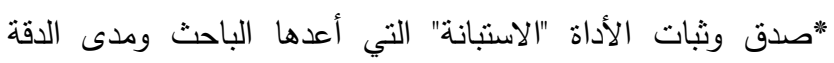
والموضوعية في استجابة أفراد العينة على فقراتها.

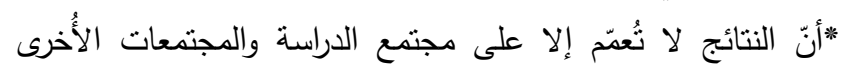
المشابهة لها ل المابر الأدب النظري والدراسات السابقة

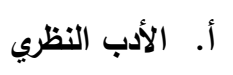

يتضمن هذا الجزء من الاراسة الأدب النظري المتعلق بموضوع الدراسة: الهواتف الذكية "النقالة": (Smartphone) تعتبر الهواتف الذكية من أهم ما أفرزته الثورة التكنولوجية وتقنيات الاتصال الحديثة والمتسارعة في عملية التواصل والتفاعل بين أفراد المجتمع على اختلاف مستويات ثقافتهم وأعمارهم، فقد أصبح الكبير والصغير؛ المتعلم وغير المتعلم يستخدمها في شؤون حياته اليومية. وقد عرّف شراحبلي (8) الهاتف الذكي (النقال) بأنه الهاتف الذي يوفر مزايا تصفح الإنترنت ومزامنة البريد الإكتروني وفتح ملفات الأوفيس ويحتوي على لوحة مفاتيح كاملة (QWERTY) إلا أنّ التعريف الأصح والأكثر قبولاً اليوم أنه الجوال الذي يعمل على أحد أنظمة التشغيل التالية: نظام ويندوز موبايل (Windows Mobile)، ونظام منيوت (MENUT) ومن مشتقاته (Assembly)، ونظام لينكس (LINUX) ومشتقاته، وبلاك بيري. وعرّف الدليمي(9) أيضاً الهواتف الذكية بأنها: وسيلة تعليمية يستخدمها المعلمون في الكثير من المدارس وتساعد الطلبة على بلى متابعة مساقاتهم الأكاديمية ومتابعة واجباتهم العلمية، ومواعيد 
الذكية في العملية التعليمية نظر لصعوبة القدرة على التقاء المعلم مع في الطالب في ظل ظروف ومتطلبات هذه الجائحة. ب. الاراسات السابقة: بستعرض هذا الجزء من الدراسة

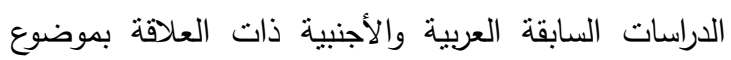

استخدام الهواتف الذكية في العملية التعليمية، وكما يلي: ولئ داتيه

\section{أ. الدراسات العربية ذات العلاقة بموضوع الدراسة:}

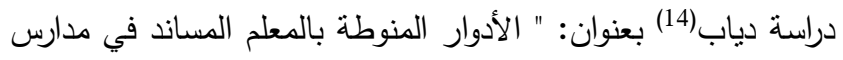

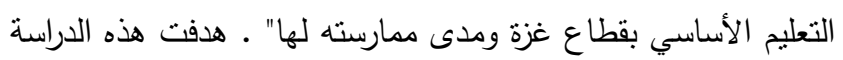

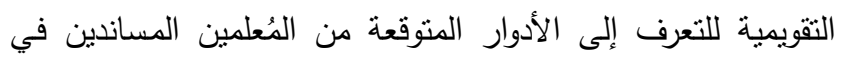
مدارس المرحلة الأساسية بقطاع غزة، الذين نم تعيين أعداد كبيرة

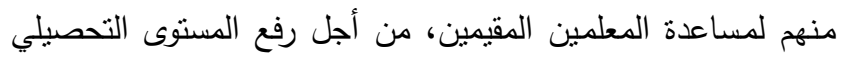

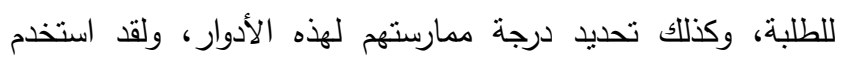
الباحثان المنهج الوصف التحليلي. وطبقت الدراسة على عينة عشوائية

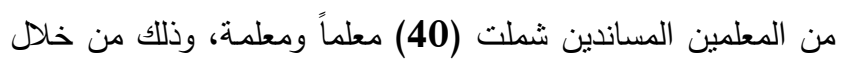

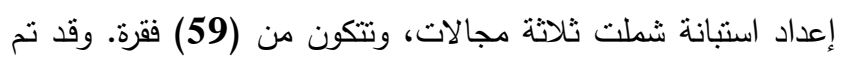

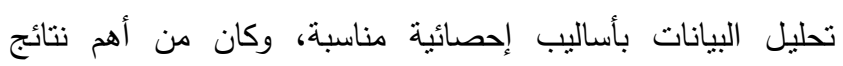

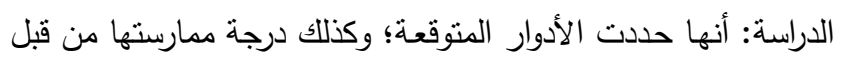
المعلم في مدارس التعليم الأساسي بقطاع غزة. دراسة مهاتي(15) بعنوان:" دور المعلم المساند في تحسين العملية

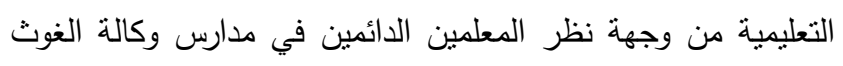

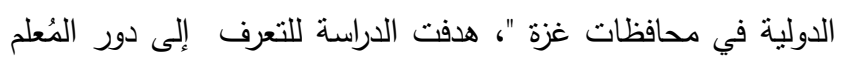

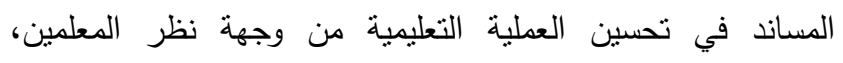
والكثف عما إذا كان هناك فروق ذات دلالة إحصائية بين متوسطات

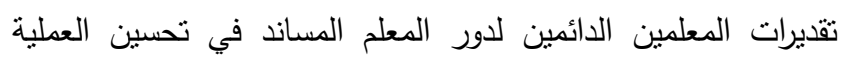

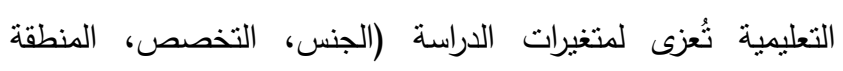

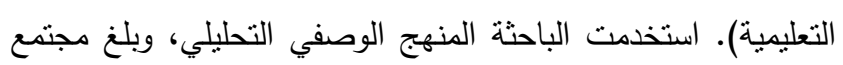

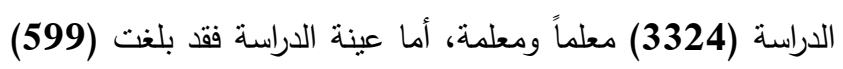

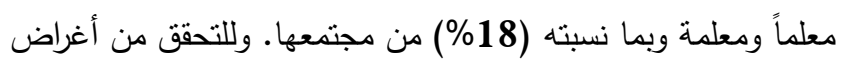

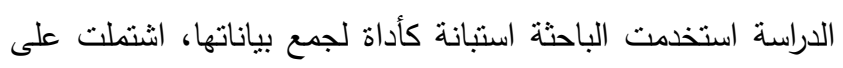

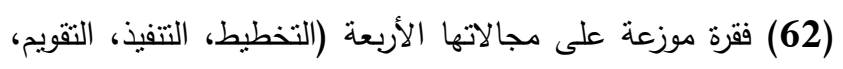

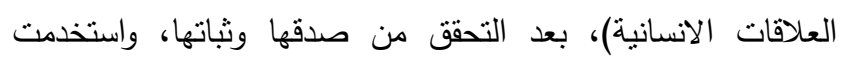
برنامج الرزم الإحصائية للعلوم الاجتماعية (SPSS) لتحليل البيانات.

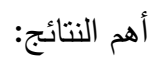
- أنّ دور المعلم المساند في مجال العلاقات الإنسانية جاء بدرجة فاعلية كبيرة، أما دوره في باقي مجالات الدراسة فكان بدرجة الدانة فاعلية منوسطة.
لتنفيذ العملية التعليمية، وشروط الأمان والسلامة العامة، وتتاسب جميع فئات الطلبة، وخاصةً الطلبة من ذوي الاحتياجات الخاصة.

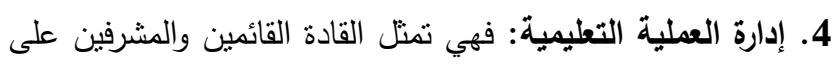

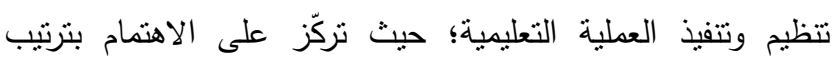

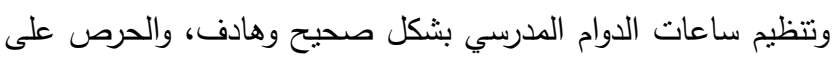
الاحترام المتبادل بين إدارة المدرسة والمعلمين، واحترام المعلمين لبعضهم البعض، وكذلك احترام المعلمين للطلبة.

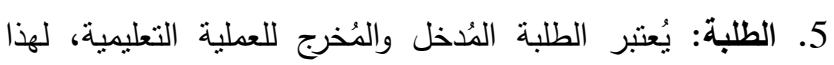
ينبغي معرفة ما يملك كل طالب من مهارات وخبرات، ومعرفة طبيعة البيئة الني يعيش فيها. 6. التمويل والتنظيم: وهو مدى تحمل الدولة للمسؤولية التي تقع على فلى التئي

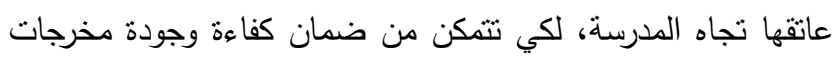

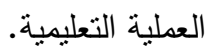

دور المعلم ضمن العملية التعليمية:

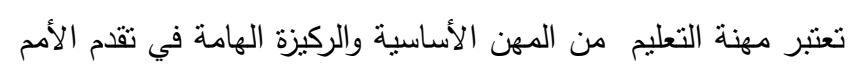
والثعوب وسيادتها فهي يُعزى رقيها وتقدمها في مجالات حياتها

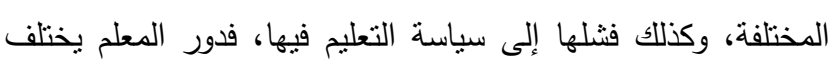

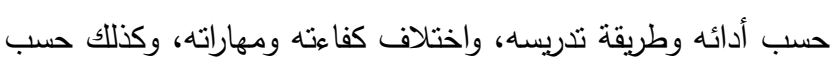

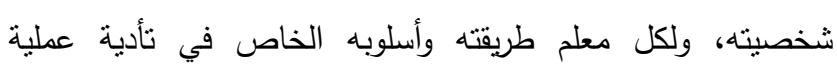
التدريس، فالأُسلوب التعليمي الذي يناسب معلماً قد لا يكون مناسباً

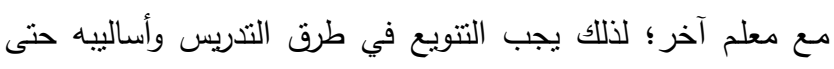

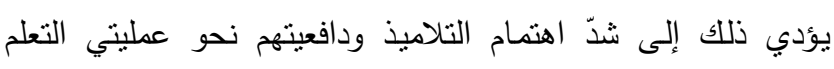

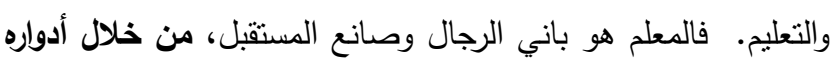

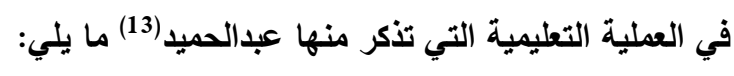

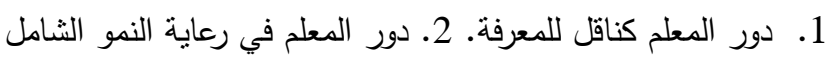
للطلبة؛ فلم يعد دوره يقتصر على تلقين ونقل المعلومات. 3.

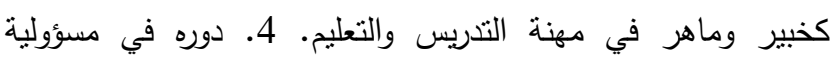

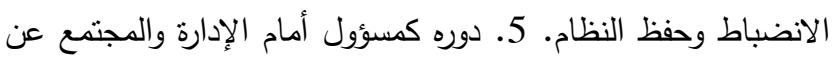
مسنوى تحصيل الطلبة وتقويمه. 6. دوره كمرشد نفسي للطلبة. 7.

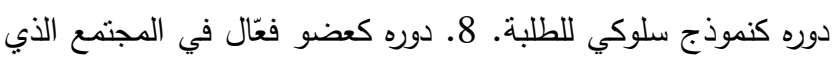

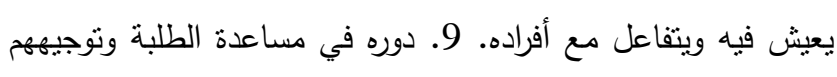

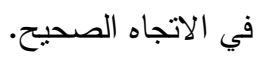
العلاقة بين العملية التعليمية والأجهزة الذكية (النقال): لقد أصبحت العلاقة بين عمليتي التعليم والتعلم في الوقت الحاضر العالئه والتقنيات التكنولوجية الحديثة وخاصة تقنيات الاتصال والتواصل التي لتئي

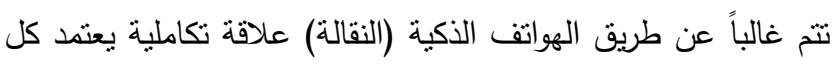

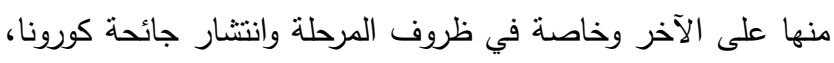
حيث أصبح التعليم عن بُعد لا يتم إلا من خلال استخدام الهواتق 
المكتملة (100) استبانة. وقد أظهرت نتائج الدراسة ما يلي: أنّ درجة

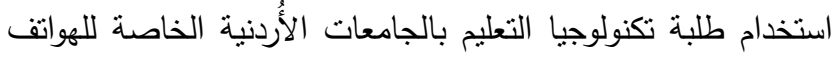

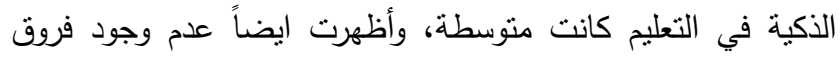
ذات دلالة إحصائية عند مستوى الدلالة (10.05 م 2 ) ) في درجة استخدام الهواتف الذكية في العملية التعليمية من وجهة نظر طلبة تكنولوجيا التعليم في الجامعات الأرُدنية الخاصة تبعاً لمتغيرات الدية من الدراسة (الجنس، والجامعة، والمرحلة الدراسية). دراسة المطيري(19) بعنوان:" واقع استخدام تطبيقات الهواتف الذكية في التئي العملية التعليمية لدى أعضاء هيئة التدريس من وجهة نظر طالبات الدراسات العليا بكلية التربية في جامعة المللك سعود"، والتي هدفت للتعرف إلى واقع استخدام تطبيقات الهواتف الذكية في العملية التعليمية لدى أعضاء هيئة التدريس من منظور طالبات الدراسات

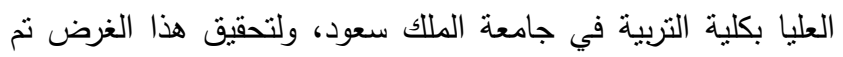

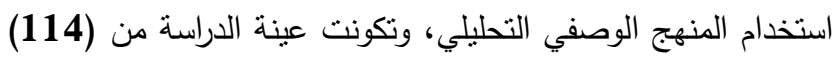

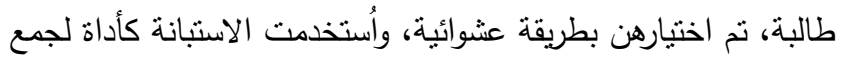
البيانات، وبعد نحليلها أظهرت نتائج الدراسة: أنّ طالبات الدراسات

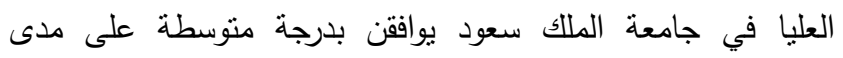
استخدام أعضاء هيئة التدريس للهواتف الذكية في العملية التعليمية، وبدرجة مرتفعة جداً على أهمية استخدام الهواتف الذكية في العملية التعليمية، وكثفت نتائج الدراسة عن وجود اتجاهات إيجابية لدى طالبات الدراسات العليا في جامعة الملك سعود نحو استخدام الهواتق الذكية في العملية التعليمية، بالإضافة إلى وجود صعوبات بلدات بدرجة متوسطة تواجه الطالبات.

ب. الدراسات الأجنبية ذات العلاقة بموضوع الدراسة:

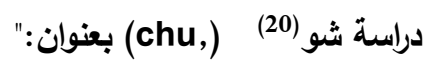

Potential Negative Effects of Mobile Learning on Students' Learning Achievement and Cognitive Load: A Format Assessment Perspective",

هدفت الدراسة إلى تحديد أثز التعلم المتتقل على التحصيل لاى الطالب وزيادة مستوى العبء المعرفي لديهم ، فقد أجريت هذه الدراسة

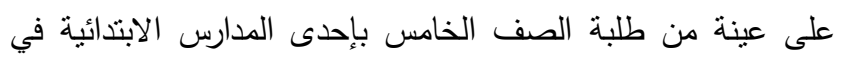

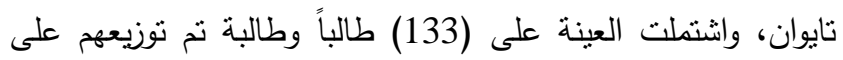
مجموعتين، الأولى تجريبية والأخرى ضابطة، وقد أسفرت النتائج عن تفوق طالب الهجوعة الضابطة على طالب المجموعة التجريبية في

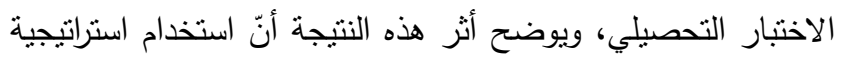

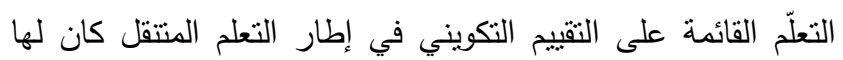
تأثبر سيء على نواتج التحصيل لدى الطلبة مقارنةً بالطريقة التقليدية.

$$
\text { دراسة أهاروني(21) (Aharony,) بعنوان:" }
$$

Library and Information (19), Science students perceptions of M-Learning ",
- أن هناك فروقاً دالة إحصائياً بين منوسطات تقديرات أفراد عينة

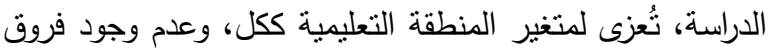
دالة إحصائياً تبعاً لمتغيري الجنس والتخصص. دراسة القايد(16) بعنوان:" اتجاهات طالبات جامعة الملك عبدالعزيز نحو استخدام الهواتف الذكية في إتاحة المعلومات الإلكترونية"، التي

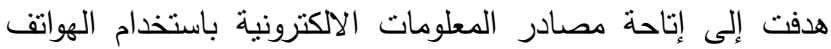

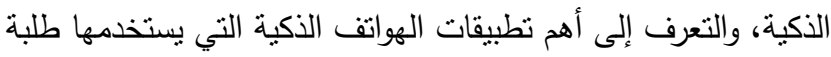
جامعة الملك عبد العزيز في إتاحة واستخدام مصادر المعلومات، وذللك من خلال استبانة لقياس تلك الاستخدامات، ولقد توصلت الدراسة الى عدة نتائج منها: أنّ اغلبية مجتمع الدراسة يستخدمون

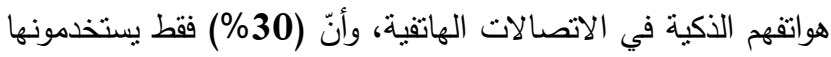
في الأغراض التعليمية والبحثية، وأنّ (76\%) من مجتمع الدراسة لم الته يستخدما خدمات الهاتف الذكي التي توفرها مكتبة الملك عبد العزيز. دراسة يوسف، رباب(17) بعنوان:" فاعلية استخدام التعليم الإكتروني توفي والهواتق الذكية في تحصيل طالبات الانتساب لكلية التربية وتتمية الاتجاهات نحوها، المؤتمر العلمي الثالث والعشرون للجمعية المصرية لللمناهج وطرق التدريس وتطوير المناهج: رؤى وتحديات"، والتي هدفت إلى دراسة فاعلية استخدام التعليم الإكتروني والهواتف الذكية لتتمية التحصيل لدى طالبات الانتساب بقسم الثقافة الإسلامية

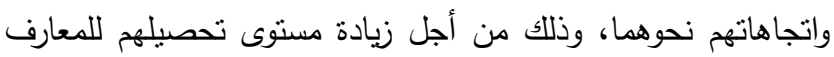
المرتبطة بالمعلومات المنضمنة في توصيف المقرر، وتتمية اتجاهات طالبات الانتساب نحو استخدام التعليم الإلكتروني والهواتف الذكية في توطي التعليم. وذلك من خلال اختبار تحصيلي لقياس مدى تحصيل الطالبات في المعلومات المتضمنة في توصيف المقرر، ومقياس

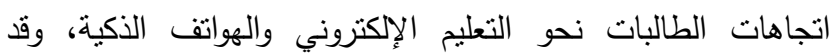

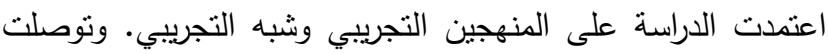
الدراسة إلى عدم وجود فروق ذات دلالة إحصائية عند مستوى الدلالة ( 1 a0.05 ) في منوسطي درجات طالبات المجموعة التجريبية والضابطة للاختبار التحصيلي للجوانب المعرفية المرتبطة بموضوعات توصيف مقرر تقنيات التعليم والاتصال. دراسة العزام(18) بعنوان: " درجة استخدام الهواتف الذكية في العملية التعليمية دراسة ميدانية من وجهة نظر طلبة تكنولوجيا التعليم في

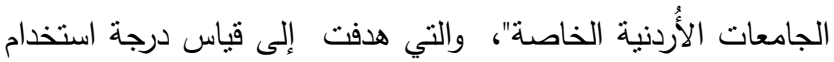

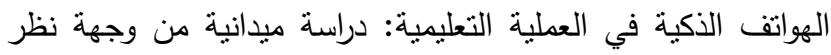

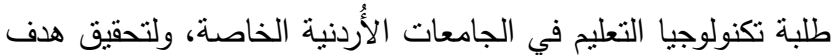
الدراسة تم تطوير أداة استبانة تتعلق بدرجه استخدام الهواتف الذكية في العملية التعليمية تتكون من (42) فقرة، واستخدام المنهج الوصفي لنافي

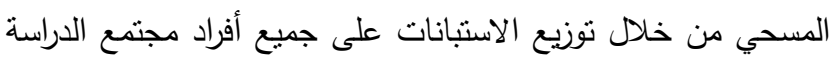

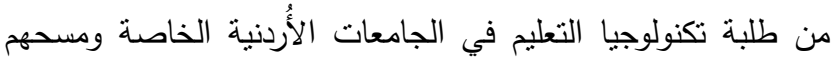
خلال العام الدراسي 2017 /2016)، وبلغ إجمالي الاستبانات 
التعقيب على الدراسات السابقة

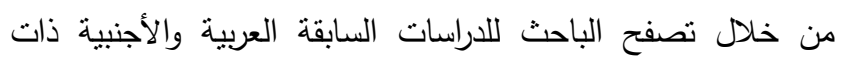

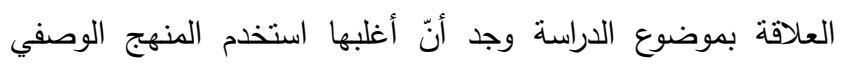

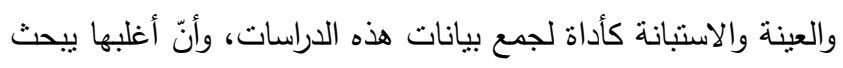

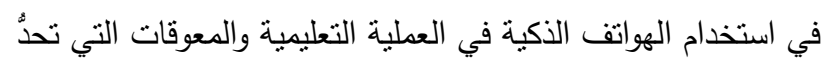

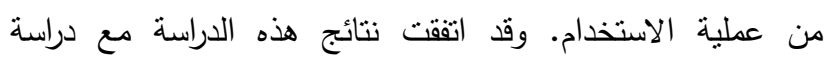
مهاتي(15) من حيث دور المعلم في توجيه الطلبة لاستخدام الهواتف

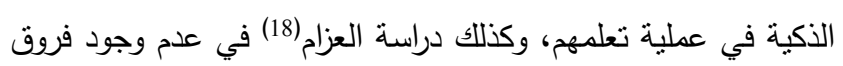

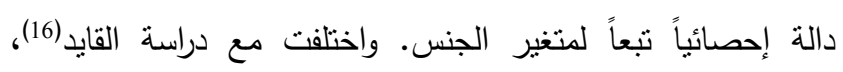

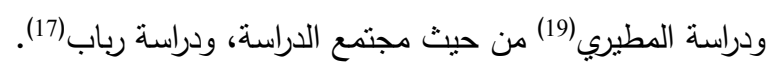
الإجراءات الميدانية للاراسة

منهجية الدراسة: استخدم الباحث المنهج الوصفي التحليلي، لملائمته

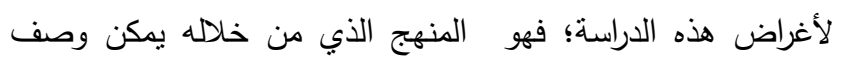

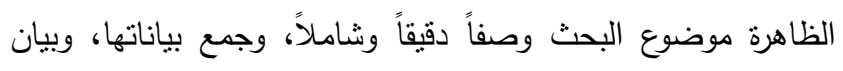

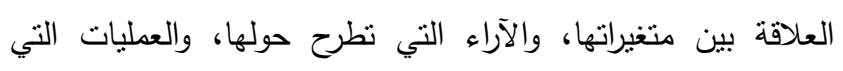

$$
\text { تتضمنها والآثار التي تحدنها. }
$$

مجتمع الدراسة: نكون مجتمع الدراسة من (2401) معلِ ومعلمة،

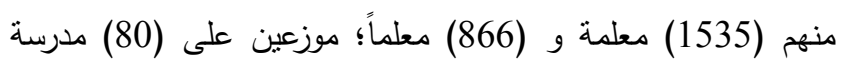

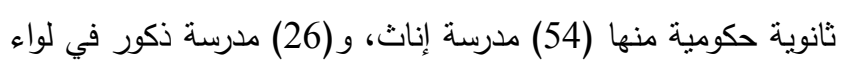

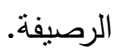
عينة الاراسة: نكونت عينة الدراسة من(360) معلماً ومعلمة، منهم (130) ذكورا، و (230) إناثا، اختارها الباحث من مجتمعها بالطريقة الطبقية العشوائية حسب جدول كرجسي و مورغان (24). والجدول (1) يوضح ذلك:
هدفت إلى الكثف عن دراية طلاب علوم المكتبات والمعلومات

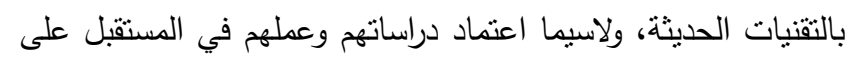
استخدام هذه التقنيات، حيث حاولت الدراسة الإجابة عن تساؤلين هما:

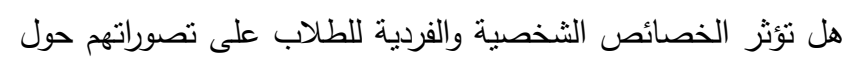

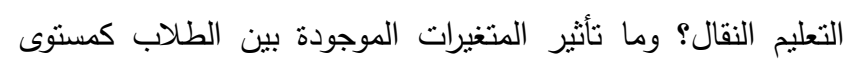

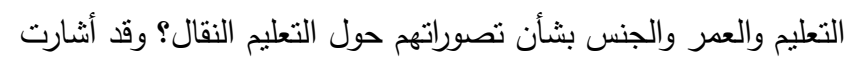

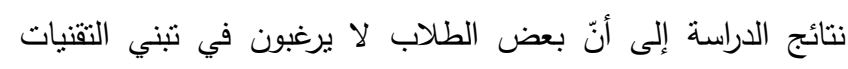

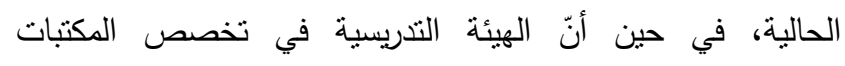

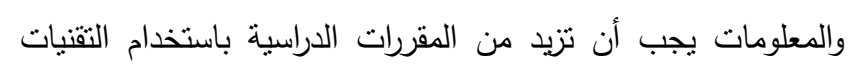
النقالة لتحقيق أقصى قدر من تعريض الطلاب لهذه المنصات. دراسة كو وآخرون(Ko, et al,) بعنوان:

" Comparative study (18) on M-Learning usage among LIS students from Hong Kong, Japan and Taiwan ",

هدفت الدراسة التعرف إلى استخدام التعليم النقال من قبل طلاب

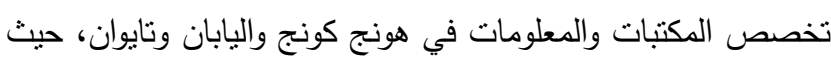

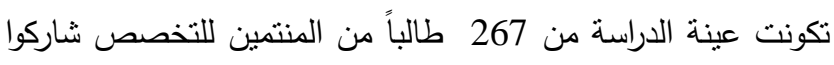

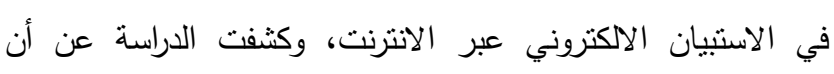

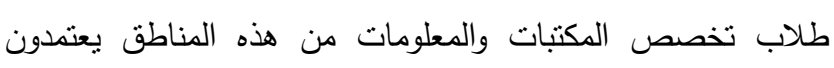

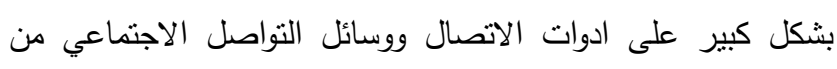

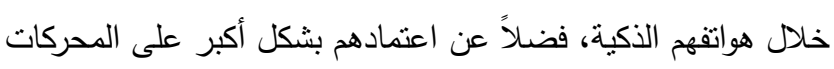

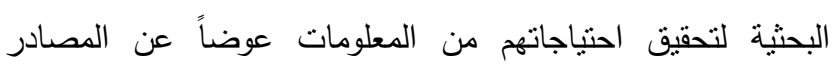
التقليدية داخل الككتبة. دراسة كالسا و بكارد) (Kalisa \& Picard,) بعنوان:" A-15 Systematic Review on Mobile Learning in Higher Education: The African Perspective ",

هدفت الدراسة إلى استعراض ومقارنة الدراسات المنشورة عن التعلم

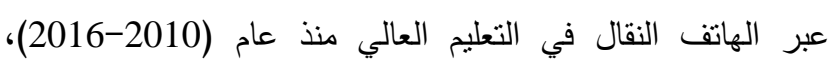

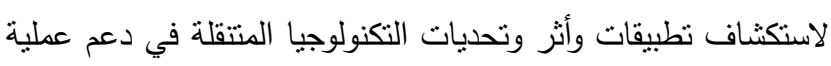

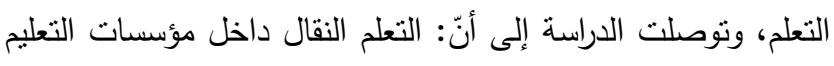

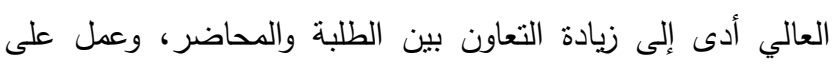

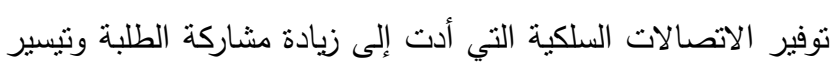

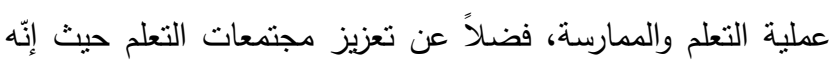

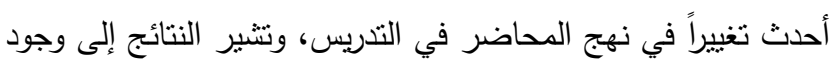

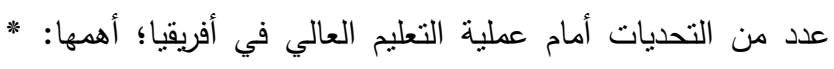

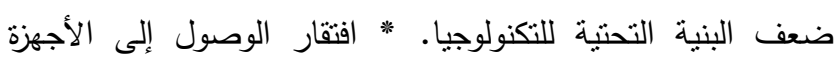
النقالة الحديثة. * ضعف مهارات التعلم النقال لدى الدحاضرين. المواقف السيئة بين الطلبة والمحاضرين. * الفتقار سياسات إدارة الجامعات لنتفيذ عملية التعلم النقال داخل الجامعات. 
الجدول (1) يبين توزيع أفراد عينة الدراسة حسب المتغيرات الثخصية

\begin{tabular}{|c|c|c|c|c|}
\hline النسبة \% & العدد & صنف المتغير & المتغير & الرق \\
\hline $36 \%$ & 130 & ذكر & \multirow{2}{*}{ الجنس } & 1 \\
\hline $64 \%$ & 230 & أُنْى & & 2 \\
\hline $100 \%$ & 360 & \multicolumn{3}{|c|}{ المجموع } \\
\hline $56 \%$ & 200 & بكالوريوس فأقل & \multirow{2}{*}{ المؤهل العلمي } & 3 \\
\hline $44 \%$ & 160 & أعلى من البكالوريوس & & 4 \\
\hline $100 \%$ & 360 & \multicolumn{3}{|c|}{ المجموع } \\
\hline $50 \%$ & 180 & 10 سنوات فأقل & \multirow{2}{*}{ سنوات الخبرة } & \\
\hline $50 \%$ & 180 & أكثر من 10 سنوات & & \\
\hline $100 \%$ & 360 & \multicolumn{3}{|c|}{ المجموع } \\
\hline
\end{tabular}

معارض بشدة)؛ وهي تمثل رقياً (5، 4، 3، 2، 1 1) على الترتيب،

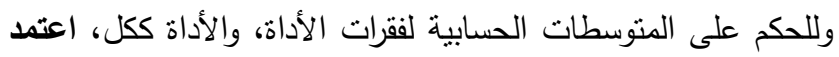
المعيار الإحصائي باستخدام معادلة طول الفئة كالآتي:

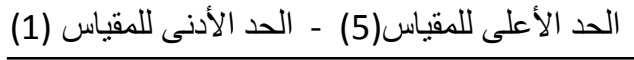

عدد الفئات المطلوبة (3) (3) - (3)

$5-1$

$1.33=$

$5-1$

3

ومن ثم إضافة الجواب (1.33) إلى نهاية كل فئة، وكما في الجدول (2) (2) (التالي:

\begin{tabular}{|c|c|}
\hline درجة ممارسة الدور & المتوسط الحسابي \\
\hline متدنية & من 1.00- 2.33 \\
\hline متوسطة & من 2.34- 3.67 \\
\hline مرتفعة & من 3.68- 5.00 \\
\hline
\end{tabular}

المعالجة الإحصائية المستخدمة: استخدمت المعالجات الإحصائية

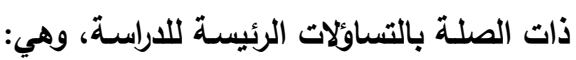

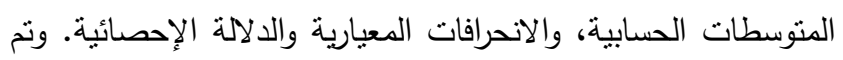

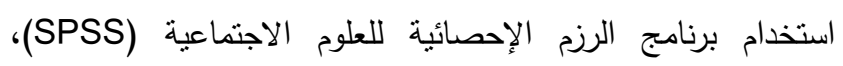
ومقياس كرونباخ-ألفا لقياس الثبات والاتساق الداخلي لأداة الدراسة، لإناءة

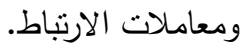

نتائج الاراسة ومناقشتنها النتائج المتعلة بالسؤال الأول والذي نصهة:

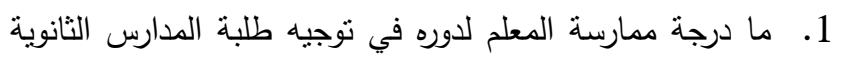

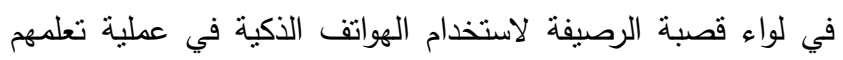

من وجهة نظرهم ؟ للإجابة عن السؤال الأول: تم استخراج المتوسطات الحسابية والانحرافات المعيارية وقيمة الاختبار (T) ومسنوى الدلالة؛ والجدول: لالإل (3) يوضح ذلك:

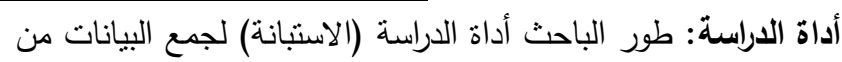

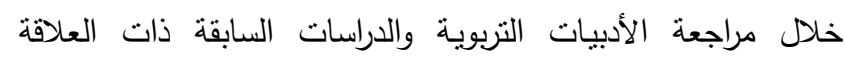

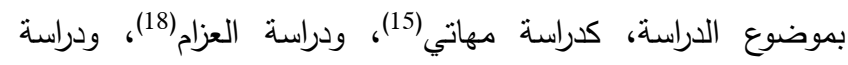
عبدالفتاح(25)، وأعطى لكل فقرة من الفقرات وزناً مدرجاً وفقاً لسلم

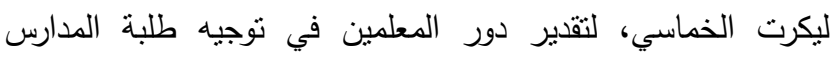
الثانوية الحكومية في لواء الرصيفة لاستخدام الهواتق الذكية في عملية تعلمهم. واشتملت الأداة بصورتها النهائية على (25) فقرة.

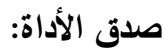
جرى التثبت من صدق الأداة بعرضها على مجموعة من المُحكمّين

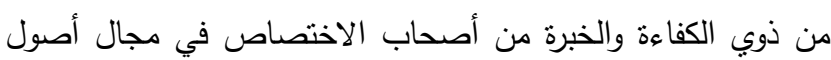

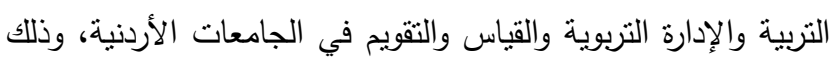

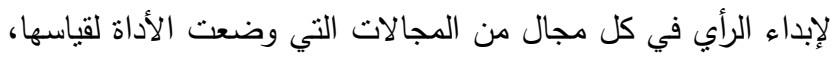

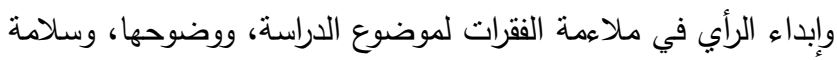

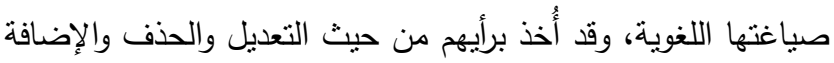

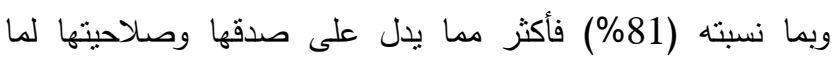
أُعدت له. ثبات الأداة: لقد تم التحقق من ثبات الأداة بطريقتين:

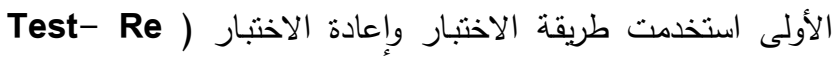

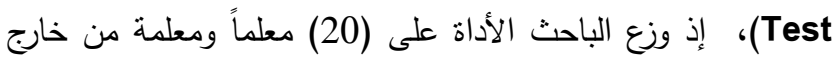

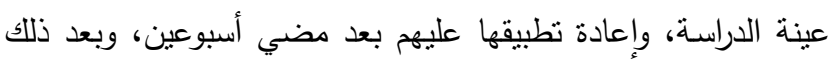

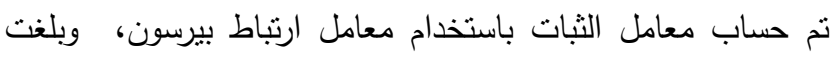

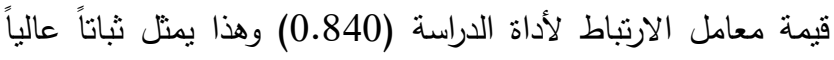

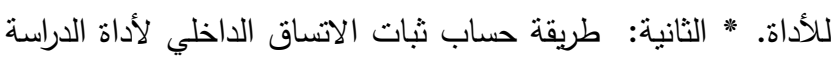

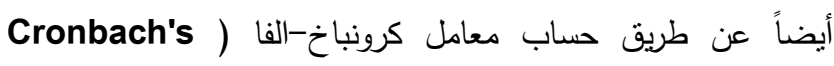
Alpha Coefficient

لغايات هذه الدراسة. تصحيح أداة الدراسة: نم اعتماد سلم ليكرت(Likert ) الخماسي

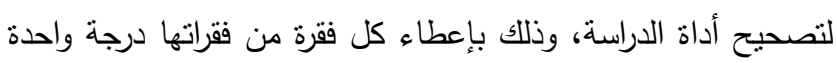
من بين درجاته الخمس (موافق بشدة، موافق، محايد، معارض، لئه 
الجدول (3) يبين المنوسطات الحسابية والانحرافات المعيارية وقيمة الاختبار (T) ومسنوى الدلالة لاستجابات أفراد عينة الدراسة

\begin{tabular}{|c|c|c|c|c|c|c|}
\hline قيمة SIG & (ختبار (T) & 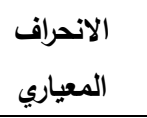 & الحستوسط & الفقرة & الرتبة & الرقم \\
\hline $0.00 *$ & 14.3 & 0.67 & 3.45 & 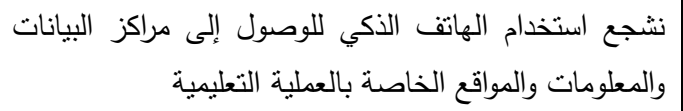 & & 1 \\
\hline $0.00 *$ & 13.4 & 0.71 & 3.51 & التعلم بالأسلوب الذبة على استخدم الهاتق الذكي كونه يساعدهم على معاتى & & 2 \\
\hline $0.00 *$ & 15.0 & 0.65 & 4.00 & 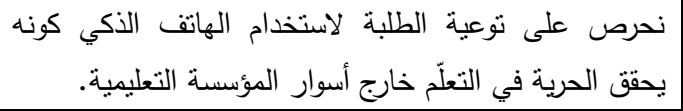 & 1 & 3 \\
\hline $0.00 *$ & 12.3 & 0.66 & 3.44 & 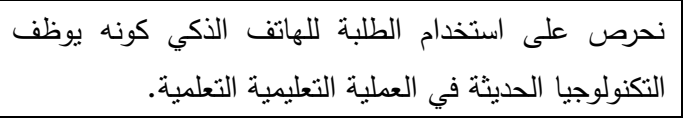 & & 4 \\
\hline $0.00 *$ & 16.3 & 0.59 & 3.76 & 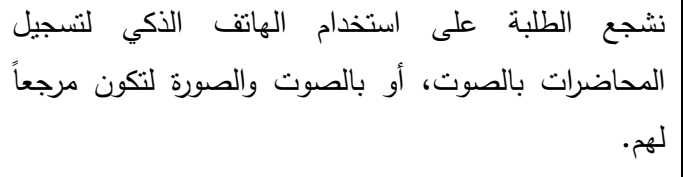 & & 5 \\
\hline $0.00 *$ & 11.3 & 0.71 & 3.59 & كورونا. & & 6 \\
\hline $0.00 *$ & 16.4 & 0.69 & 3.52 & يخص في متابعة الاعلانات التيل الطلبة على كيفية استخدام الهاتف النقال & & 7 \\
\hline $0.00 *$ & 14.7 & 0.64 & 3.55 & نُشعر الطلبة بأن استخدم الهاتق الذكي يزيد من دافعيتهم & & 8 \\
\hline $0.00 *$ & 15.6 & 0.67 & 2.45 & 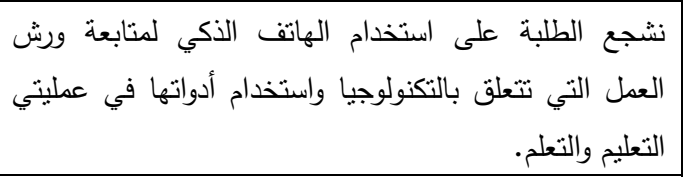 & & 9 \\
\hline $0.00 *$ & 14.5 & 0.66 & 3.33 & الدحاضرات على الاختبارات والواجبات الصفاتف الذكي ل لتسيق مواعيد & & 10 \\
\hline $0.00 *$ & 13.3 & 0.80 & 3.46 & من الطريقة الثقليدية في التعليم. الهندام الهاتق الذكي أكثر جاذبية ومتعة & & 11 \\
\hline $0.00 *$ & 14.5 & 0.71 & 2.32 & نشليمية آلنة لدى الطلىة. & 25 & 12 \\
\hline $0.00 *$ & 13.4 & 0.76 & 3.60 & نواصل عبر المواقع مع أستاذ المادة لتبادل المعلومات إنتاء مجموعات & & 13 \\
\hline $0.00 *$ & 14.6 & 0.58 & 3.22 & 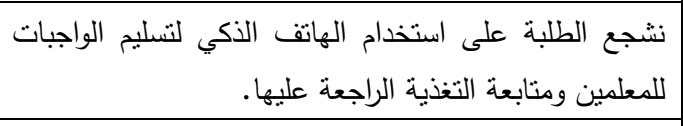 & & 14 \\
\hline $0.00 *$ & 13.6 & 0.52 & 3.41 & 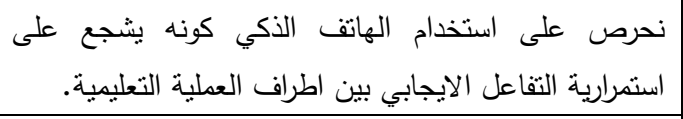 & & 15 \\
\hline $0.00 *$ & 15.1 & 0.68 & 3.54 & 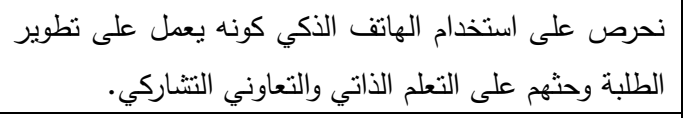 & & 16 \\
\hline $0.00 *$ & 15.3 & 0.70 & 3.42 & 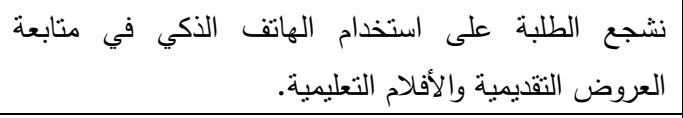 & & 17 \\
\hline $0.00^{*}$ & 12.4 & 0.57 & 3.10 & نشجع الطلبة على استخدام الهاتق الذكي لإرسال الاعلانات & & 18 \\
\hline
\end{tabular}


المجلة الدولية لضمان الجودة - المجلد الرابع، العدد الثاني، 2021.

\begin{tabular}{|c|c|c|c|c|c|c|}
\hline قيمة SIG & اختبار (T) & الانحراف & الحسابي & الفقرة & الرتبة & الرقم \\
\hline & & & & والاخبار الطارئة والمستعجلة للزملاء. & & \\
\hline $0.00 \%$ & 12.5 & 0.72 & 3.60 & 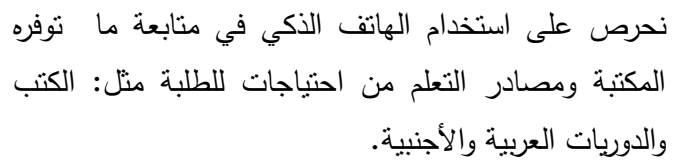 & & 19 \\
\hline 0.00 * & 13.5 & 0.57 & 2.68 & 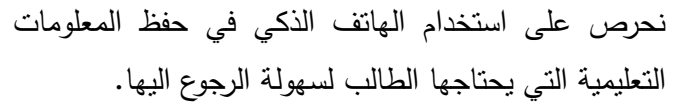 & & 20 \\
\hline $0.00 \%$ & 13.7 & 0.61 & 3.43 & نشجع استخدام الهاتف الذكي لالتقاط الصور ومقاطع الفيديو & & 21 \\
\hline $0.00 \%$ & 14.0 & 0.77 & 3.61 & في منتابعة بعض استخدام الهاتف الذكي كونه يبعدهم عن الخجل & & 22 \\
\hline $0.00 *$ & 15.1 & 0.57 & 3.34 & مع الزملاء لأغراض على استخدام الهاتق الذكي لتبادل الرسائل النصية & & 23 \\
\hline $0.00 \%$ & 12.8 & 0.64 & 3.44 & نحرص على استخدام الهاتف الذكي لأنه يعزز ميول الإبداع & & 24 \\
\hline $0.00 *$ & 15.1 & 0.60 & 3.45 & والدراسات بصرص على استخدام الطلبة للهاتف الذكي لتصفح الكتب & & 25 \\
\hline $0.00 \%$ & 14.6 & 0.65 & 3.37 & \multicolumn{3}{|c|}{ الدرجة الكلية } \\
\hline
\end{tabular}

النتائج المتعلقة بالسؤال الثاني والذي نصه: هل نوجد فروق ذات دلالة إحصائية عند مستوى الدلالة (0.05 م 0 2) بين استجابات أفراد العينة حول دور المعلم في توجيه طلبة المدارس الثانوية الحكومية في لواء قصبة الرصيفة لاستخدام الهواتف الذكية في عملية تعلمه تبعاً

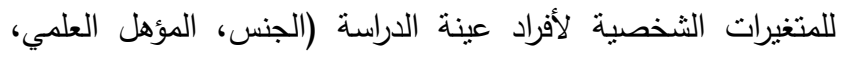
(الخبرة) ؟ للإجابة عن السؤال الرئيس الثاني، الأي يتفرع عنه الأسئلة التالية: السؤال الفرعي الأول: هل توجد فروق ذات دلالة إحصائية عند

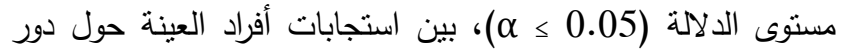
المعلم في عملية توجيه طلبة المدارس الثانوية الحكومية في لواء الرصيفة لاستخدام الهواتف الذكية في عملية تعلمهم، تبعاً لمتغير

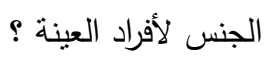
للإجابة عن السؤال الفرعي الأول: تم استخراج المتوسطات الحسابية والانحرافات المعيارية وقيمة الاختبار (T) ومستوى الدلالة، وهذا يوضحه الجدول (4) التالي: جدول رقم (4) يوضح المتوسطات والانحرافات المعياري وقيمة

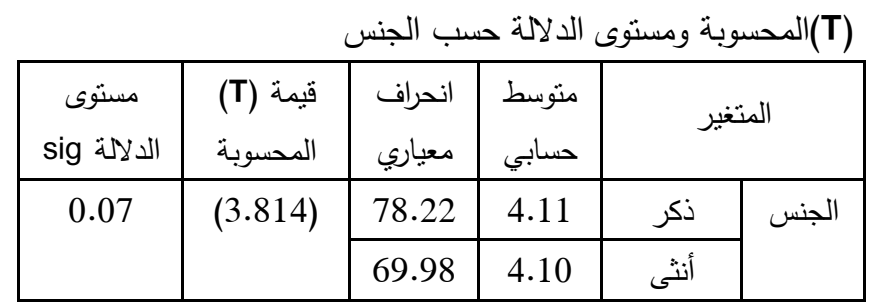

يتضح من الجدول(3) أعلاه، أنّ المتوسطات الحسابية لاستجابات أفراد عينة الدراسة على فقرات الاستبانة تراوحت بين (2.32-4.00)، وأنّ المتوسط الحسابي الكلي لجميع الفقرات ( 3.37)، وهو يقع ضمن الدور المتوسط من الممارسة في عملية التوجيه لاستخدام الهواتف الذكية من قبل طلبة المدارس الثانوية الحكومية في لواء قصبة الرصيفة في عملية تعلمهم، أما بالنسبة لقيمة الاختبار (T) فهي تساوي(14.6) وانّ القيمة الاحتمالية (sig) تساوي (0.00*). وقد احتلت الفقرة رقم (3) والتي نصها:" نحرص على توعية الطلبة لاستخدام الهاتف الذكي كونه يحقق الحرية في التعلّم خارج أسوار المؤسسة التحليمية"، المرتبة الأولى وبوسط حسابي (4.00) وضمن الدرجة المرتفعة. وفي المرتبة الأخيرة جاءت الفقرة رقم (12) والتي نصها:" نشجع الطلبة على استخدام الهاتف الذكي كونه بوفر بيئة تعليمية آمنة لدى الطلبة". وبوسط حسابي بلغ (2.32) وهي ضمن الدرجة المتننية. وتُعزى هذه النتيجة لارجة الممارسة المتوسطة لدور المعلم في توجيه طلبة المدارس الثانوية الحكومية لاستخدام الهواتف الذكية في عملية تعلمهم؛ لحرص المعلمين على تشجيع الطلبة لاستخدام الهواتف في عملية تعلمهم، وربما هناك ضعف في عمليتي الإرشاد والتوعية من قبل القائمين على المدارس الثانوية في لواء الرصيفة للمعلمين والطلبة، وذللك لظروف الحظر، وضعف إمكانية التقاء المعلمين مع الطلبة بسبب جائحة كورونا. 
جدول رقم (6) يوضح المتوسطات والانحراف المعباري وقيمة (T) المحسوبة

\begin{tabular}{|c|c|c|c|c|c|}
\hline & & لدلالة & ومس & & \\
\hline مستوى & قيمة (T) & انحراف & متوسط & \multirow{2}{*}{\multicolumn{2}{|c|}{ المتغير }} \\
\hline الدلالة & المحسوبة & معياري & حسابي & & \\
\hline \multirow{3}{*}{0.08} & \multirow{3}{*}{3.430} & & & 10 سنوات & \multirow{3}{*}{ الخبرة } \\
\hline & & 00.12 & 50 & فأقَّل & \\
\hline & & 78.45 & 3.97 & أكثر من 10 & \\
\hline
\end{tabular}

يلاحظ من الجدول رقم (6) أعلاه أنّ قيمة (T) المحسوبة (3.430)

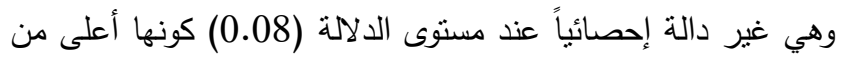
(0.05)، إضافة إلى تقارب المتوسطات الحسابية إلى حد كبير • وهذا

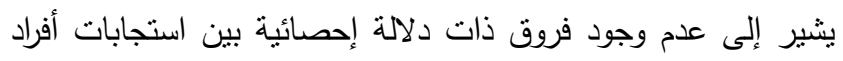
العينة، حول دور المعلم في توجيه طلبة الددارس الثانوية الحكومية في لواء الرصيفة لاستخدام الهواتف الذكية في عملية تعلمه، تبعاً

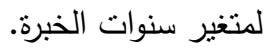

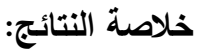

أظهرت نتائج الدراسة أنّ هناك دوراً للمعلم في عملية توجيه طلبة المدارس الثانوية الحكومية في لواء قصبة الرصيفة لاستخدام الهواتف

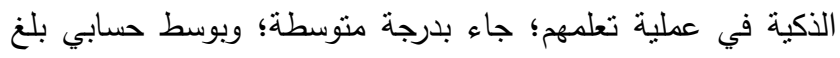
(3.37) من وجهة نظر أفراد عينة الدراسة. كما أظهرت النتائج أيضاً عدم وجود فروق ذات دلالة إحصائية عند مستوى الدلالة (0.05 الدات م) بين منوسطات نقديرات أفراد عينة الدراسة حول دور المعلم في عملية توجيه طلبة الدارس الثانوية الحكومية في لواء قصبة الرصيفة

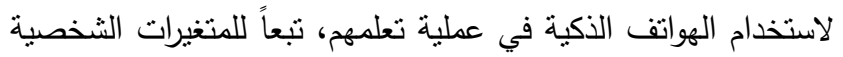
لأفراد عينة الدراسة : الجنس والمؤهل العلمي وسنوات الخبرة.

التوصبيات: ويناءً على النتائج توصي الاراسة بما يالي: * عقد دورات خاصة لكل من الطلبة والمدرسين لكيفية استخدام كافة النقتيات التكنولوجية المتاحة وخاصة الهواتف النقالة (الذكية) في العملية التعليمية. * تحفيز الطلبة على الاستخدام الأمتل للهواتق الذكية في عملية تعلمهح؛ متل إعطائهم واجبات تحثهم على استخدام هذه الهواتف. * إطلاع إدارة المدارس الثانوية والطلبة والمعلمين على نتائج مثل هذه الدراسة التي قد تتفعهم في الارتقاء بمستوى وعيهم بدرجة استخدامهم للهواتق الذكية في عملية التعليم والتعلم . ويقترح الباحث إجراء دراسات تجريبية تبين مدى أهمية استخدام الهاتف الذكي في التعليم والتعلم.
"يتضح من خلال الجدول (4) أعلاه، أن قيمة (T) المحسوبة" (3.814)، غير دالة إحصائياً عند مسنوى الدلالة (0.07) كونها أكبر من (0.05)، وكذللك هناك تقارب في الدتوسطات الحسابية بين الذكور

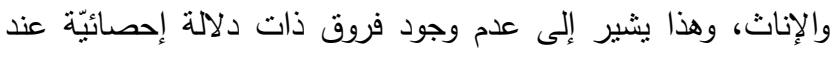

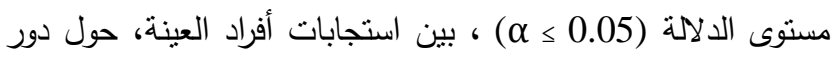
المعلم في توجيه طلبة الددارس الثانوية في لواء قصبة الرصيفة لاستخدام الهواتف الذكية في عملية تعلمهم، تبعاً لمتغير الجنس.

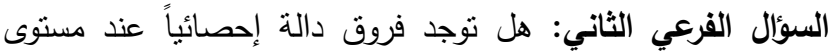

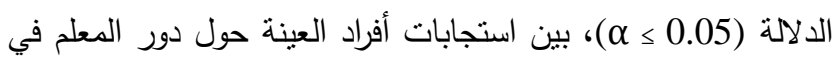

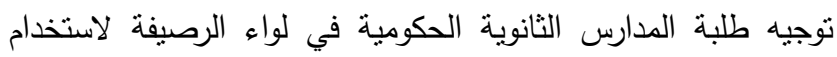

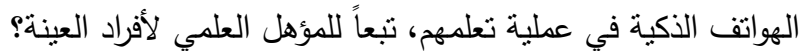
للإجابة عن السؤال الفرعي الثاني: تم استخراج المنوسطات الحسابية

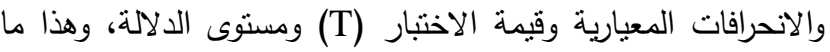

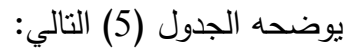

جدول (5) يوضح المنوسط الحسابي والانحراف المعياري وقيمة (T) المحسوبة ومستوى الدلالة

\begin{tabular}{|c|c|c|c|c|c|}
\hline & & & & \multicolumn{2}{|c|}{ المتغير } \\
\hline \multirow[t]{2}{*}{0.08} & 4.560 & 80.71 & 4.48 & بكالوريوس & \multirow{2}{*}{ العؤهل } \\
\hline & & 78.80 & 4.49 & أعلى من & \\
\hline
\end{tabular}

يتضح من خلال الجدول رقم (5) أعلاه أنّ قيمة (T) الححسوبة

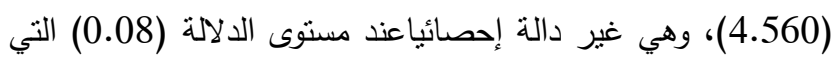
تعتبر أعلى من (0.05)، وكذلك هناك تقارب بالمتوسطات الحسابية. وهذا يثير إلى عدم وجود فروق دالة إحصائياً، بين استجابات أفراد العينة حول دور المعلم في توجيه طلبة المدارس الثانوية الحكومية

لاستخدام الهواتف الذكية في عملية تعلمهم، تبعاً للمؤهل العلمي.

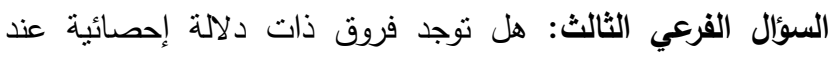

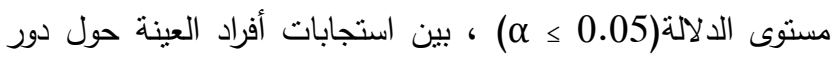
المعلم في توجيه طلبة المدارس الثانوية الحكومية في لواء الرصيفة لاستخدام الهواتف الذكية في عملية تعلمهم، تبعاً لعدد سنوات الخبرة ؟

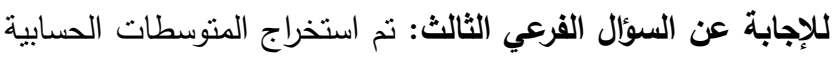

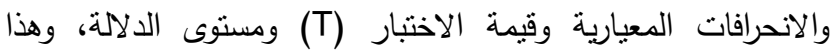

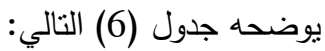


School of the Future, University Book House, Al Ain, United Arab Emirates (2005).

12) Jaber, previous reference.

13) Abdel Hamid, Randa. The role of the teacher in the educational process. Website: https://www.mqaal.com, (2020).

14) Diab, Sohail. The teacher we want, his Scientific standing and roles, a paper presented to the Sixth Conference of Yarmouk University, held in November, Irbid, pp. 218-230, (2005).

15) Mahati, Randa Nimr Tawfiq. The role of the supporting teacher in improving the educational process from the point of view of permanent teachers in UNRWA schools in the governorates of Gaza, a master's thesis submitted to: College of Graduate Studies, Islamic University of Gaza, (2010). 16) Al-Qayed, Ishraq Qayed. Attitudes of King Abdulaziz female students towards the use of smart phones in providing electronic information, a master's thesis, submitted to the College of Graduate Studies, King Abdulaziz University, Jeddah, Saudi Arabia, (2014).

17) Youssef, Rabab Abdel-Maqsoud. The Effectiveness of Using E-Learning and Smartphones in the Achievement of Female Students Affiliate to the College of Education and the Development of Attitudes Towards It, Twentythird Scientific Conference of the Egyptian Association for Curricula, Teaching Methods and Curriculum Development: Visions and Challenges, (2014).

18) Al-Azzam, Faryal Nagy. The degree of using smartphones in the educational process, a field study from the point of view of educational technology students in private Jordanian universities, a master's thesis, submitted to the College of Graduate Studies, Al Ummah Middle East University, Jordan, (2017).

\section{References:}

1) Sari, Helmy Khader. Internet Culture: A Study in Social Communication, The Jordanian Ministry of Culture, Amman, Jordan, (2009).

2) Al-Tamimi, Abdullah Muhammad Reda. The reasons behind the spread of BlackBerry devices and the educational implications of that from the point of view of secondary school students in the Abu Dhabi Educational District, Abu Dhabi: Abu Dhabi Education Council, Abu Dhabi Education District, (2011).

3) Chen, Y- Fan. \& Katz, James E. Extending family to school life: college students use of the mobile phone. Human Computer Studies, 67, 179191, (2009)

4 ) Al-Mahdi, Saleh. Virtual Education, New University House, Alexandria, Arab Republic of Egypt, (2008).

5) Al-Badri, Tariq Abdel Hamid. classroom education management, House of Culture for Publishing and Distribution, Amman, Jordan, (2005). 6) Al-Dulaimi, Abdul Razzaq Muhammad. Media and Globalization, 1st Edition, Al-Raed Scientific Library, Amman, pp. 6-34, (2006).

7) Jaber, Alaa'. Elements of the educational process, topic site: https://www.mawdoo3.com, (2018).

8) Sharhabli, Muhammed Ateyyah. Educational benefits of using smartphones and tablets in the educational process, available at: http://www.mohdary.blogspot.com/2013/12/smartphones-tabletc.html\#.VFkGGfmUdWg, (2013)

9) Al-Dulaimi, previous reference.

10) Al-Kiswani, Mustafa et al. Classroom Learning Management, Dar Safaa for Publishing and Distribution, Amman, Jordan, (2005).

11) Astal, Ibrahim and Al-Khalidi, Ferial. The teaching profession and the teacher's roles in the 
19) Al-Mutairi, Sultan bin Huwaidi. The reality of using smart phone applications in the educational process of faculty members from the point of view of graduate students at the College of Education at King Saud University, Journal of Scientific Research in Education, 8(20), PP. 107-137., (2019).

20) Chu, H.C. Potential Negative Effects of Mobile Learning on Students' Learning Achievement and Cognitive Load: A Format Assessment Perspective. Educational Technology \& Society, 17 (1), PP. 332-344, (2014).

21) Aharony, Noa. Library and Information (19), Science students perceptions of M-Learning, Journal of librarianship and information science, 46(1), 48-61, (2014).

22) Ko, Eddie HT. et al., Comparative study (18) on M-Learning usage among LIS students from Hong Kong, Japan and Taiwan, The Journal of Academic Librarianship, 41(5), 567-577, (2015).

23) Kaliisa, Rogers \& Picard, Michelle, A-15 Systematic Review on Mobile Learning in Higher Education: The African Perspective. Turkish Online Journal of Educational Technology-TOJET, 16(1), PP. 1-18, (2017).

24) Krejcie, R. \& Morgan, D. Determining Sample size for research activities, Educational and Psychological Measurement, (30), 607-610, (1970).

25) Abdel-Fattah, Bashayer Ibrahim Abdel-Ghani. The degree of Jordanian university students' use of smartphones in education in quality standards, a master's thesis submitted to: College of Graduate Studies, Middle East University, Jordan, (2019). 